\title{
Economic benefits of implementing patient- centered medical home among patients with hypertension
}

This article was published in the following Dove Press journal:

ClinicoEconomics and Outcomes Research

\author{
Ziyad S Almalki' \\ Abrar A Alotaibi ${ }^{2}$ \\ Wejdan S Alzaidi ${ }^{2}$ \\ Afnan A Alghamdi ${ }^{2}$ \\ Abdulrahman M Bahowirth ${ }^{3}$ \\ Noura M Alsalamah ${ }^{4}$ \\ 'Department of Clinical Pharmacy, \\ College of Pharmacy, Prince Sattam \\ Bin Abdulaziz University, Al-Kharj, \\ Riyadh, Saudi Arabia; ${ }^{2}$ Department \\ of Clinical Pharmacy, College of \\ Pharmacy, Taif University, Taif, Mecca, \\ Saudi Arabia; ${ }^{3}$ Department of Clinical \\ Pharmacy, College of Pharmacy, Umm \\ Al-Qura University, Mecca, Saudi \\ Arabia; ${ }^{4}$ Department of Clinical \\ Pharmacy, College of Pharmacy, \\ Qassim University, Buraydah, Qassim, \\ Saudi Arabia
}

Introduction: Despite the strong evidence of an association between adoption of the patientcentered medical home (PCMH) and improved clinical outcomes among patients with hypertension, evidence for associations between the PCMH and health care utilization and cost reduction within the general adult population with hypertension is less developed.

Objective: This study was designed to examine the effect of PCMH on health service expenditures and utilization in a national sample of the US adult population who were diagnosed with hypertension.

Methods: The 2010-2015 Medical Expenditure Panel Survey data were used. The study sample was limited to adults ( $\geq 18$ years) diagnosed with essential hypertension. We investigated the impact of PCMH on the direct hypertension-related total and on the costs of inpatient stays, prescription medications, outpatient visits, emergency room visits, office-based services, and other medical expenditures by using log-transformed multiple linear regression models and the propensity score method.

Results: Of the 18,630 adults identified with hypertension, $19.2 \%(n=3,583)$ of them had received PCMH care from 2010 to 2015. After matching, the no PCMH group showed greater mean in all hypertension-related health service costs and utilization. After adjusting for the remaining confounders, the PCMH group showed a significant association with lower total costs, office-based services, number of office-based visits, and outpatient visits compared with the control group. Conclusion: A significant relationship between experiencing PCMH care and a lower total health care expenditure was found in patients with hypertension.

Keywords: PCMH, hypertension, health care expenditure, MEPS

\section{Introduction}

Hypertension is a serious problem in USA that increases the burden of cardiovascular disease and leads to death. ${ }^{1}$ Despite the overall improvement in the awareness and treatment of hypertension, one-third of American adults has hypertension and only about half $(52.5 \%)$ of them have their blood pressure under control. Hypertension is considered a risk factor for heart diseases and premature mortality. According to estimates for the year 2014, more than 410,000 Americans die from hypertension, representing $15.6 \%$ of all deaths. ${ }^{2}$ Managing hypertension is also costly to the US health care system. In 2015, approximately $\$ 68$ billion was the national burden of high blood pressure. ${ }^{3}$

A chronic condition such as hypertension requires a great deal of management through diet, exercise, and monitoring the blood pressure levels. Controlling the
Correspondence: Ziyad S Almalki Department of Clinical Pharmacy, College of Pharmacy, Prince Sattam Bin Abdulaziz University, PO Box 173, Al-Kharj, Riyadh

I 1942, Saudi Arabia

Tel +966 II 5886059

Email z.almalki@psau.edu.sa 
blood pressure is seen as the key to reducing cardiovascular morbidity and mortality and avoidable health care costs. ${ }^{4}$ To achieve this goal, leading primary care organizations proposed improvements in the mode of delivery of primary care from the usual primary care to the patient-centered medical home (PCMH). ${ }^{5}$ The PCMH model is an advanced primary care model that aims to improve patient health outcomes by providing resources needed to support successful management of chronic diseases, such as hypertension. ${ }^{6-8}$

Over the past 2 decades, much research has documented the effectiveness of $\mathrm{PCMH}$ in reducing the use and cost of health care in a variety of settings and populations. For example, some studies demonstrated that PCMH implementation led to the reduction in payments for health care generally and for emergency department (ED) costs. ${ }^{8-10}$ Other studies have confirmed the clear reduction in health care utilization, specifically ED visits, primary care visits, specialist visits, inpatient admissions, or hospitalizations. ${ }^{1-16}$ In the context of hypertension, several studies have reported a significant improvement in blood pressure levels among people who experienced PCMH care. ${ }^{17-19}$

However, there has been a dearth of rigorous evidence for state and federal policy makers about whether implementing PCMH saves money and provides cost-effective care at the population level, especially for an important chronic disease such as hypertension. Despite the convincing evidence of an association between PCMH implementation and improved clinical outcomes among patients with hypertension, evidence for associations between the PCMH and health care utilization and cost reduction within the general adult population with hypertension is less developed. The finding of this study will be important to both primary care providers, who are investing time and energy to implement the $\mathrm{PCMH}$, and third-party payers, who work to minimize health-related costs on investments supporting practice transitions to the PCMH. Therefore, we initiated the first national study to address this gap by examining the economic benefit of PCMH implementation on health service utilization and cost in the national sample that includes adults of all ages who were diagnosed with hypertension.

\section{Methods}

\section{Data source}

We conducted a retrospective cross-sectional case-control using the 2010-2015 Medical Expenditure Panel Survey (MEPS). MEPS is a nationally representative survey of the civilian noninstitutionalized adult population of all ages in USA, conducted by the Agency for Healthcare Research and
Quality (AHRQ). MEPS collects comprehensive data on self-reported patient demographics, use of health services, comorbidities, health status, access to care, and other data as well; specifically, the data capture all the health services a respondent used, including inpatient, outpatient, emergency room, office-based provider, and prescription drugs and which medical condition they were linked to. MEPS is a deidentified, publicly available data that is intended for research purposes; therefore, it is exempt from the Institutional Review Board (IRB) approval. Details regarding the data and a description of its survey design are provided elsewhere. ${ }^{20}$

The survey has the following four components: the Household Component (HC), the Medical Provider Component, the Insurance Component, and the Nursing Home Component. For the aims of this study, we used only HC. Within this component, eight files for each year were retrieved (ie, the full-year consolidated data file, medical conditions data file, and the event data files for hospital inpatient stays, emergency room visits, outpatient visits, office-based medical provider visits, prescription medications, and other medical expenses) from 2010 to 2015 . Then, all files were consolidated to obtain the final dataset for the analyses. We included several years in the analyses to help to increase the precision of estimates and produce estimates with high reliability. ${ }^{21}$

\section{Study population}

We limited the study population to those aged 18 years and older with diagnoses for essential hypertension identified by the MEPS medical conditions file using the variable "CCCODEX" labeled clinical classification code. MEPS derived the CCCODEX variable by using the Clinical Classifications Software (CCS) disease categorization scheme for ICD-9-CM codes developed by the Healthcare Cost and Utilization Project under the sponsorships of the Agency for Healthcare Research and Quality. CCS collapsed ICD9-CM's multitude of codes into fewer clinically meaningful categories. To identify those with essential hypertension, we used the CCS code "98", which aggregated the ICD-9-CM diagnosis codes 401.1 and 401.9 into a single category. ${ }^{22}$ According to MEPS documentation, patients in each year may be used as independent observations since each year's information is nationally representative. ${ }^{23}$ The final study sample included individuals who had usual care providers (ie, individuals who reported having usual care providers during the interviews). Of the 115,629 MEPS individuals, 18,630 adults aged $\geq 18$ years with a diagnosis of hypertension and reported to have a usual care provider were identified for the analyses (excluded adults aged $<18$ years, $n=35,668$; with 
nonhypertensive, $\mathrm{n}=34,126$; and with no usual care providers, $n=27,205$ ). Patients were then categorized into the following two groups: a group who had access to $\mathrm{PCMH}$ (PCMH group) and a group who had no access to PCMH (no PCMH group). The two groups were then tested for the differences in several variables, and then, they were matched for further analyses.

\section{Dependent variables}

The dependent variables measure the direct hypertensionrelated total as well as inpatient stays, prescription medications, outpatient visits, emergency room visits, office visits, and other medical expenditures.

\section{Independent variables}

The main independent variable was a $(0,1)$ indicator for whether the individual had access to care consistent with PCMH principles. The PCMH care was defined using the provider-related questionnaires in MEPS. Using AHRQ's definition as the basis, we determined whether respondents had a PCMH if they reported that they received comprehensive, patient-centered, and accessible care. ${ }^{24}$ All survey items used to construct our PCMH features are defined in Table 1. These questions have been used previously in different studies to detect the access to PCMH care. ${ }^{25-28}$

We determined that the care received by an individual was a comprehensive care if the provider 1) usually asks about medications and treatments prescribed by other doctors; 2) provides care for new health problems; 3 ) provides preventive health care; 4) offers referrals to other health professionals; and 5) provides care for ongoing health problems. We considered an individual to have received patient-centered care if the provider 1) shows respect for the medical, traditional, and alternative treatments that other doctors may give; 2) explains all health care options to the individual; and 3) asks the individual to help make the treatment choice. We determined that care was accessible if the provider 1) can be easily contacted by phone about a health problem during regular office hours; 2) offers night and weekend office hours; and 3) speaks the participant's language or provided translation services. Participants with responses of "do not know", "refused", or "not ascertained" to the question were left out of the final sample.

\section{Other covariates}

The behavioral model of health care access developed by Andersen ${ }^{29}$ was utilized to account for the effects of predisposing, enabling, and need factors on access to PCMH care. These factors have been identified to be the most influential determinants explaining the quality and quantity of health services' utilization by the individual. ${ }^{30}$ Predisposing factors investigated in this study included age, sex, race, marital status, and education years. Enabling factors consisted of health insurance, employment status, family income, and census region. Health needs were measured using a dichotomous perceived health status measure (poor/fair or good/excellent) and detected chronic conditions (hyperlipidemia, mood disorders, diabetes mellitus, upper respiratory conditions, arthritis, asthma, and coronary artery disease) an individual had.

\section{Data extraction}

To precisely assess the reduction in the expenditure attributed to access to PCMH, the two study groups must be as similar as possible so that the only difference between the two can be attributed to access to PCMH care.

Table I MEPS survey items, by PCMH features

\begin{tabular}{|l|l|}
\hline PCMH criteria & Survey items used \\
\hline Comprehensive care & \\
\hline & Does the provider usually ask about medications and treatments prescribed by other doctors? \\
\hline & Does the provider provide care for new health problems? \\
\hline & Does the provider provide preventive health care? \\
\hline & Does the provider provide referrals to other health professionals? \\
\hline & Does the provider provide care for ongoing health problems? \\
\hline & \\
\hline & Does the provider show respect for the medical, traditional, and alternative treatments other doctors may give? \\
\hline & Does the provider explain all health care options to participant? \\
\hline Accessible care & Does the provider ask participant to help decide treatment choice? \\
\hline & \\
\hline & Is it difficult to contact the provider by phone about a health problem during regular office hours? \\
\hline & Does the provider offer night and weekend office hours? \\
\hline & Does the provider speak the participant's language or provide translation services? \\
\hline
\end{tabular}

Abbreviations: MEPS, Medical Expenditure Panel Surveys; PCMH, patient-centered medical home. 
A propensity score was used to estimate the expenditure difference between the case group and the control group. The propensity score was defined as the conditional probability of being assigned to the PCMH group given the covariates. Patients in the case and control groups with nearly equal propensity scores will tend to minimize the sample selection differences so that we can remove the bias in the background covariates. With the same propensity scores, we could imagine that paired case and control subjects are randomly assigned to each group.

For this study, patients with hypertension who did not receive PCMH care were matched by the caliper (also called radius) matching algorithm. The nearest neighbor matching with caliper (20\% of SD) approach was used to create two balanced comparative groups conditional on observed characteristics. The caliper matching algorithm is similar to the nearest matching algorithm except that a maximum propensity score distance is imposed. ${ }^{31}$ This means that matches are only considered within a certain radius, and this eliminates the possibility of matches being too far away.

Briefly, in our study, the first individual who had access to $\mathrm{PCMH}$ was selected and, then, we found the control (who had no access to PCMH care) with the closest propensity score. The individuals in the two study groups who were not matched were removed from the study sample. For this propensity score algorithm, whether the individual had access to PCMH was the dependent variable, while the independent variables were age, sex, marital status, education years, health insurance, employment status, family income, and census region, self-reported health, and chronic conditions.

\section{Data analysis}

Three types of analyses were conducted. First, to match each individual in the PCMH group to his/her closest control, the caliper matching algorithm, which used nearest-neighbor matching (1:1) on the estimated propensity scores, was used. Second, the weighted percentages and their corresponding 95\% CIs for all variables were calculated before and after matching by using the Rao-Scott Chi-squared test (a designadjusted Pearson Chi-squared test). Third, we calculated the unadjusted mean of each health service category's cost and utilization by PCMH status. Finally, because the cost data were skewed, linear regression models with Log transformation in the expenditure data were used to assess the impact of PCMH on health service use and expenditure by testing for differences between two groups in means. Direct health care expenditure and use variables were used as dependent variables, while age, sex, race, education years, census region, family income, employment status, health insurance, self-reported health, and calendar year were used as the independent variables. For this modeling, gamma distribution and a log link were used to get a consistent estimation of coefficients and marginal effects of having access to PCMH. A modified Park test was used to identify the appropriate model for the analysis.

To account for the MEPS's complex survey design, all analyses were adjusted for design elements, including weights, clustering, and stratification provided by the data collection agency to obtain national estimates. The parameter estimates from the regression were converted to adjusted OR, and their corresponding 95\% CIs were computed. A two-sided $P$-value of 0.05 was used to determine statistical significance. As the sampling design of MEPS is not from a simple random sampling process but from a complex sampling design, we used person-specific sampling weight based on the US census data for all our estimates to adjust for the complex sample design and nonresponse. All statistical analyses were conducted using the SAS 9.4 software (SAS Institute Inc., Cary, NC, USA).

\section{Results}

Table 2 presents the difference in demographic characteristics and health status of the study population before and after matching and with or without PCMH use. A total of 3,583 individuals with hypertension had access to PCMH care, while 15,047 individuals had no access to PCMH care.

Table 3 reports the total and mean of health service use including office-based and outpatient, ED, inpatient, prescription, and other medical uses in 2017 dollars. The mean total medical expenditures for the PCMH group are approximately $\$ 9,598$, while the expenditure for their matched counterparts is $\$ 9,699$. Those who had PCMH access had a lower annual mean in expenditures on office-based visits, outpatient visits, ED visits, and other medical expenses. In this sample, the no PCMH group had a greater use for each category of service.

Table 4 shows the estimation of the PCMH impact on direct health care expenditure and use associated with hypertension by PCMH access. There is a significant decrease in total expenditures among people who received PCMH (11\%) compared to people who did not receive PCMH. Among health service categories, the outpatient $(19 \%)$ and office expenditure $(14 \%)$ were the most significant reductions among the PCMH group. PCMH was significantly associated with the lower utilization of office visits and outpatient visits. PCMH was associated with $14 \%$ fewer office visits and $14 \%$ fewer outpatient visits. 


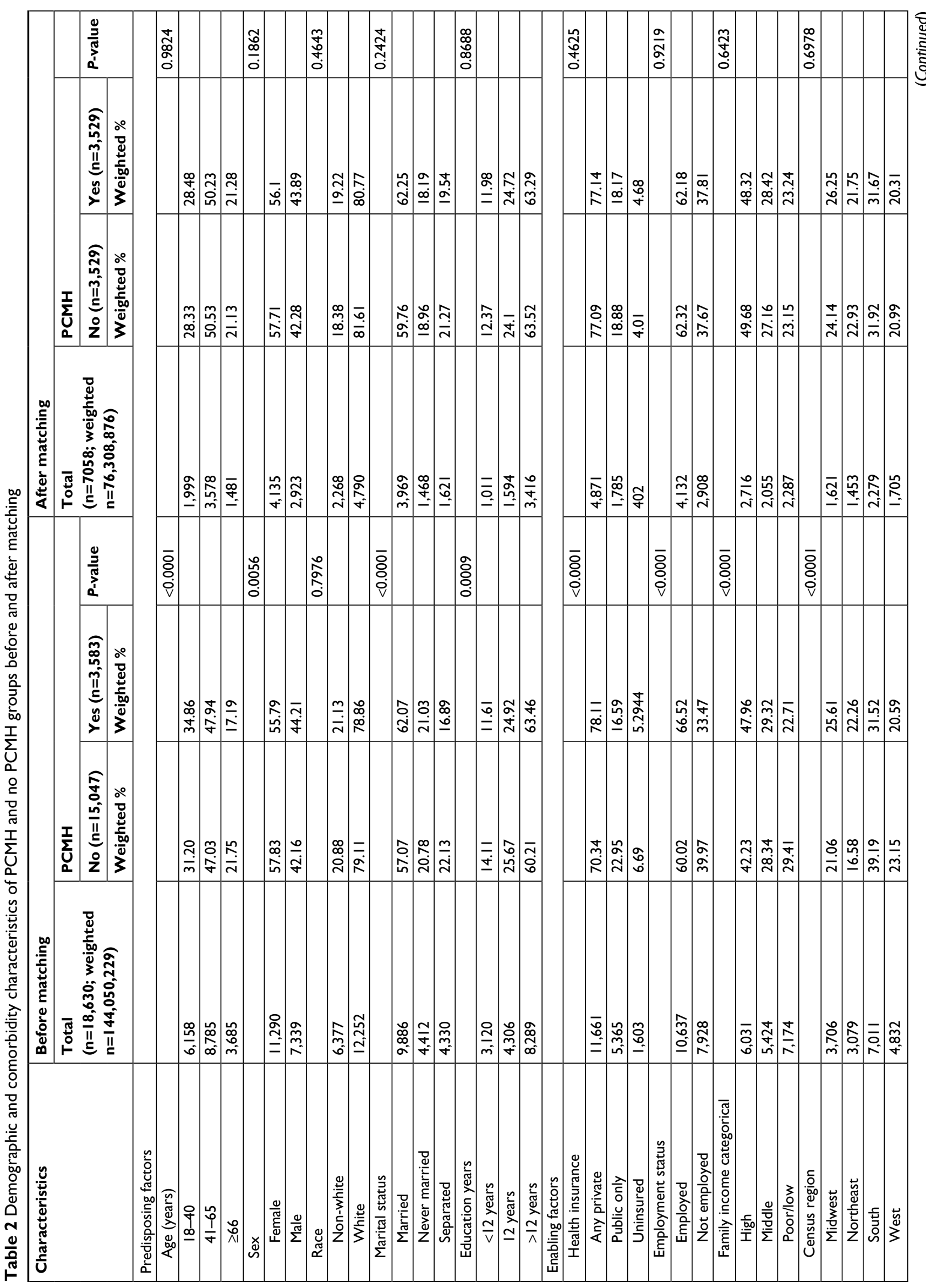




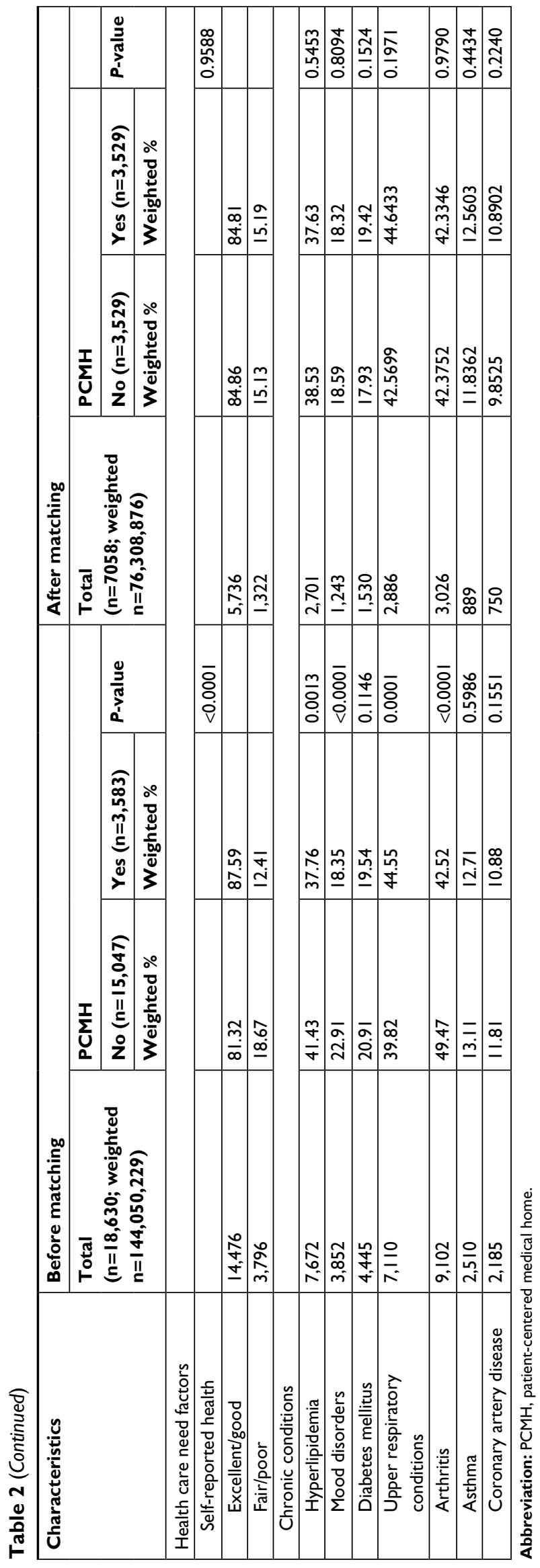

\section{Discussion}

In this nationally representative sample of US adults diagnosed with hypertension, we found that access to $\mathrm{PCMH}$, as defined in this study, was associated with a positive effect in reducing overall hypertension-related health care utilization and cost. Specifically, the findings showed PCMH associated with a lower incidence of office-based and outpatient visits and, thus, their associated costs. We found no appreciable difference in the mean of other service categories.

These findings were supported by other researches reporting that chronically ill patients accessing PCMH care lower their odds of utilizing outpatient settings (ie, office-based physicians and outpatient clinics). ${ }^{32}$ This may be attributed to the added benefit of PCMH to the management and control coordination of care of chronic conditions, such as hypertension, that would lead to a significant reduction in the volume of the workload in these settings. Another explanation for this observation is that some interventions were primarily delivered by telephone- and online-based communications between health care providers and their patients as a function of PCMH service to expand access to care and provide a continuity of care in the follow-up of individuals. ${ }^{33}$

Although after adjusting for all possible covariates, experiencing PCMH care was associated with lower ED or inpatient hospital expenditures, these expenditures were not significantly lower. This could be explained by medical need. Adjustment for health status and other comorbidities in the propensity score may not fully account for acute medical needs that are not preventable even with high-quality primary care. ${ }^{34}$

In our sample, we found that only $19.2 \%$ had access to PCMH care. The major reason for the observed limited access to PCMH is the payment method. Consistently, the field of primary care is seen as underpaid, overworked, and faced with an increasingly complex patient population. ${ }^{35-37}$ The current payment model does not allow practices to benefit financially from any improvements in utilization, costs, and quality. Its potential depends in part on how effectively financial incentives can be realigned to encourage several payment changes to primary care providers that have been implemented to better align payment with the establishment of PCMHs. Multiple payment approaches took on a variety of forms and have evolved over time, such as fee-for-service (FFS), shared savings, blended payment models, comprehensive payment model, and grant-based payments. ${ }^{38-40}$ However, these payment models may not fully support all PCMH functions. ${ }^{41}$ New payment models should be developed and implemented that increase affordability and, thus, facilitate 
Table 3 Expenditures and utilization by PCMH status after matching $(n=7,058)$

\begin{tabular}{|c|c|c|c|c|c|c|c|c|}
\hline \multirow{3}{*}{$\begin{array}{l}\text { Variable } \\
\text { Total expenditures, \$ }\end{array}$} & \multicolumn{4}{|l|}{ PCMH } & \multicolumn{4}{|l|}{ No PCMH } \\
\hline & \multirow{2}{*}{ 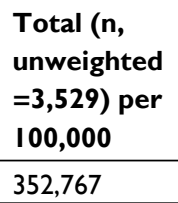 } & \multirow{2}{*}{\begin{tabular}{|l|} 
Mean \\
9,598 \\
\end{tabular}} & \multicolumn{2}{|c|}{$95 \% \mathrm{Cl}$} & \multirow{2}{*}{$\begin{array}{l}\text { Total }(n, \\
\text { unweighted } \\
=3,529) \text { per } \\
100,000 \\
383,585\end{array}$} & \multirow{2}{*}{\begin{tabular}{|l|} 
Mean \\
9,699 \\
\end{tabular}} & \multicolumn{2}{|c|}{$95 \% \mathrm{Cl}$} \\
\hline & & & 8,843 & 10,352 & & & 8,804 & 10,595 \\
\hline Office-based expenditures, $\$$ & 117,603 & 3,134 & 2,885 & 3,383 & 134,578 & 3,469 & 3,174 & 3,764 \\
\hline Outpatient expenditures, $\$$ & 50,485 & $\mathrm{I}, 484$ & $\mathrm{I}, 197$ & $\mathrm{I}, 772$ & 54,583 & 1,521 & $\mathrm{I}, 12 \mathrm{I}$ & 1,921 \\
\hline ED expenditures, $\$$ & 20,970 & 571 & 437 & 704 & 22,319 & 586 & 488 & 683 \\
\hline Inpatient expenditures, \$ & 151,155 & 22,562 & 19,360 & 25,764 & 158,497 & 22,231 & 19,408 & 25,053 \\
\hline Prescription expenditures, $\$$ & 2,464 & 167 & 148 & 185 & 2,631 & 172 & 152 & 193 \\
\hline Other medical expenses, $\$$ & 10,090 & 272 & 208 & 335 & $\mathrm{II}, 187$ & 291 & 251 & 332 \\
\hline Office-based visits, $n$ & 563 & 15.02 & 14.05 & 16.00 & 663 & 17.11 & 15.83 & 18.39 \\
\hline Outpatient visits, $n$ & 50 & 1.33 & 1.14 & 1.53 & 63 & 1.64 & 1.37 & 1.90 \\
\hline ED visits, $n$ & 18 & 0.48 & 0.44 & 0.53 & 19 & 0.50 & 0.46 & 0.55 \\
\hline Inpatient stays, nights, n & 49 & 1.27 & 1.05 & 1.49 & 51 & 1.37 & 1.13 & 1.61 \\
\hline Prescriptions, $\mathrm{n}$ & 55 & 3.75 & 3.59 & 3.91 & 61 & 4.02 & 3.86 & 4.19 \\
\hline
\end{tabular}

Abbreviations: ED, emergency department; PCMH, patient-centered medical home.

Table 4 Results of regression analysis to estimate the $\mathrm{PCMH}$ impact on direct health care expenditure and use $\mathrm{e}^{\mathrm{a}}$

\begin{tabular}{|l|l|l|l|l|}
\hline Category & $\begin{array}{l}\text { Estimate } \\
\text { PCMH } \\
\text { vs no } \\
\text { PCMH }\end{array}$ & \multicolumn{2}{l|}{ 95\% Cl } & P-value \\
\hline Total expenditures \$ & 0.89 & $0.8 \mathrm{I}$ & 0.99 & 0.03 \\
\hline Office-based expenditures \$ & 0.86 & 0.77 & 0.96 & 0.0 I \\
\hline Outpatient expenditures \$ & $0.8 \mathrm{I}$ & 0.74 & 0.98 & 0.03 \\
\hline ED expenditures \$ & 0.92 & 0.76 & $\mathrm{I} .1 \mathrm{I}$ & 0.39 \\
\hline Inpatient expenditures \$ & 0.83 & 0.65 & $\mathrm{I} .06$ & 0.10 \\
\hline Prescription expenditures & 0.99 & 0.86 & $\mathrm{I} .13$ & 0.88 \\
\hline Other medical expenses \$ & 0.89 & 0.73 & $\mathrm{I} .09$ & 0.29 \\
\hline Office-based visits & 0.86 & 0.80 & 0.93 & 0.0004 \\
\hline Outpatient visits & 0.86 & $0.8 \mathrm{I}$ & $0.9 \mathrm{I}$ & $0.00 \mathrm{I}$ \\
\hline ED visits & 0.98 & 0.97 & $\mathrm{I} .00$ & $0.3 \mathrm{I}$ \\
\hline Inpatient stays & 0.87 & 0.64 & $\mathrm{I} .19$ & 0.054 \\
\hline Prescriptions & 0.98 & 0.94 & $\mathrm{I} .02$ & 0.45 \\
\hline
\end{tabular}

Note: ${ }^{a}$ Adjusted for age, sex, race, education years, census region, family income, employment status, health insurance, self-reported health, and calendar year.

Abbreviations: ED, emergency department; $\mathrm{PCMH}$, patient-centered medical home.

access to PCMH. Most importantly, the new payment reforms must reward and reimburse the PCMH care team and recognize the care coordination, evaluation, and follow-up with patients through email or phone. ${ }^{42}$

Improved access to PCMH care will not be achievable with payment reform alone. Clinicians play a critical role in the success and development of PCMH. There is an extreme fragmentation in the delivery system. For example, the efforts between health care providers are poorly coordinated and the ability to share current and accurate information across these providers is lacking. ${ }^{43}$ The more complex the care, the more opportunities there are for communication gaps, inadequate sharing of medical information, and medical errors. ${ }^{44}$ Therefore, it is important for the health care providers to exchange information, preferences, goals, and experiences in a patient's care as a key factor of high quality and more efficient care..$^{45}$

Our study has several strengths. First, the study data represent a nationally representative $U$ sample. Second, although unmeasured confounding is possible in this observational study, we adjusted for a wide range of factors that may affect health care utilization. Third, MEPS was unique in its inclusion of the PCMH-related survey items, which permits the investigation on the presence of the PCMH through the respondents' responses.

Despite the strength of this study, the study has several limitations. First, MEPS data used in this study were self-reported, which may be subject to recall bias. ${ }^{46}$ Other methods, such as direct reports from patients, might have provided different estimates. Second, the analysis in this study was restricted to the components of the PCMH that could be measured in MEPS and did not include information about the structural features of the primary care practices (eg, adoption of electronic health records, use of evidence-based clinical protocols, and process of care transitioning), which could potentially influence the health care outcomes. ${ }^{28}$ Third, adults who were homeless, institutionalized, or living in nursing homes were excluded from MEPS; thus, our estimate may be ungeneralizable to these subpopulations as those groups 
were reported to have higher rates of hypertension. ${ }^{47,48}$ Last, although this research is not able to control for the quality of PCMH care and services, one might consider the role of quality of care when interpreting the results.

\section{Conclusion}

The results of MEPS data analyses suggested that there was a significant association between having implemented PCMH and having lower total health care costs. This finding is to be expected given research suggesting positive associations between having PCMH and controlling blood pressure in adults with hypertension. ${ }^{17-19}$ The improvement in blood pressure control may be a result of team-based, patient-centered, coordinated, and continuous care through the PCMH model that helped these patients receive more appropriate health services and, consequently, improved their health. ${ }^{49}$ The importance of these findings is heightened by the Affordable Care Act's (ACA) significant coverage expansion initiatives, ${ }^{50}$ which are expected to significantly increase the number of Americans, especially those suffering from chronic diseases, who will need access to $\mathrm{PCMH}$ care. Thus, it is important to figure out whether the advanced PCMH care model works under the current payment reform and how the payment systems could better support all functions of the PCMH model by rewarding the providers for delivering high value, patient-centered primary care.

\section{Acknowledgments}

The authors would like to thank the Saudi Association for Scientific Research (SASR) for providing their intellectual, technical, and logistical support throughout the duration of the project. The abstract of this article was presented as a poster presentation at the 23rd Annual Meeting of the International Society of Pharmacoeconomics and Outcomes Research, Baltimore, Maryland, May 2018. The poster abstract was published in Value in Health.

\section{Disclosure}

The authors report no conflicts of interest in this work.

\section{References}

1. Armstrong C; Joint National Committee. JNC8 guidelines for the management of hypertension in adults. Am Fam Physician. 2014;90(7):503-504.

2. Centers for Disease Control and Prevention, National Center for Health Statistics [homepage on the Internet]. Underlying Cause of Death 1999-2013 on CDC WONDER Online Database, released 2015. Data are from the Multiple Cause of Death Files, 1999-2013, as compiled from data provided by the 57 vital statistics jurisdictions through the Vital Statistics Cooperative Program. Available from: http://wonder. cdc.gov/ucd-icd10.html. Accessed February 23, 2018.
3. Benjamin EJ, Blaha MJ, Chiuve SE; American Heart Association Statistics Committee and Stroke Statistics Subcommittee. Heart disease and stroke statistics - 2017 update: a report from the American Heart Association. Circulation. 2017;135(10):e146-e603.

4. Elliott WJ. The Economic Impact of Hypertension. J Clin Hypertens. 2003;5(3):3-13.

5. Robert Graham Center, Policy Studies in Family Medicine and Primary Care. "The Patient Centered Medical Home: History, Seven Core Features, Evidence, and Transformational Change,” November 2007. Available from: https://www.graham-center.org/dam/rgc/documents/ publications-reports/monographs-books/rgcmo-medical-home.pdf. Accessed February 24, 2018.

6. Patient-Centered Primary Care Collaborative [homepage on the Internet]. Defining the medical home. Available from: https://www.pcpcc. org/about/medical-home. Accessed January 6, 2018.

7. Ferrante JM, Balasubramanian BA, Hudson SV, Crabtree BF. Principles of the patient-centered medical home and preventive services delivery. Ann Fam Med. 2010;8(2):108-116.

8. Berenson RA, Hammons T, Gans DN, et al. A house is not a home: keeping patients at the center of practice redesign. Health Aff (Millwood). 2008;27(5):1219-1230.

9. Pines JM, Keyes V, van Hasselt M, McCall N. Emergency department and inpatient hospital use by Medicare beneficiaries in patient-centered medical homes. Ann Emerg Med. 2015;65(6):652-660.

10. Beal A, Hernandez S, Doty M. Latino access to the patient-centered medical home. J Gen Intern Med. 2009;24(Suppl 3):514-520.

11. Clarke R, Bharmal N, Di Capua P, et al. Innovative approach to patientcentered care coordination in primary care practices. Am J Manag Care. 2015;21(9):623-630.

12. Christensen AL, Zickafoose JS, Natzke B, McMorrow S, Ireys HT. Associations between practice-reported medical homeness and health care utilization among publicly insured children. Acad Pediatr. 2015;15(3):267-274.

13. Yoon J, Liu CF, Lo J, et al. Early changes in VA medical home components and utilization. Am J Manag Care. 2015;21(3):197-204.

14. Randall I, Mohr DC, Maynard C. VHA Patient-Centered Medical Home Associated With Lower Rate of Hospitalizations and Specialty Care Among Veterans With Posttraumatic Stress Disorder. J Healthcare Qual. 2017;39(3):168-176.

15. Kaushal R, Edwards A, Kern LM. Association between the patientcentered medical home and healthcare utilization. Am J Manag Care. 2015;21(5):378-386.

16. Friedberg MW, Rosenthal MB, Werner RM, Volpp KG, Schneider EC. Effects of a Medical Home and Shared Savings Intervention on Quality and Utilization of Care. JAMA Intern Med. 2015;175(8):1362-1368.

17. Rosenthal MB, Alidina S, Friedberg MW, et al. A Difference-in-Difference Analysis of Changes in Quality, Utilization and Cost Following the Colorado Multi-Payer Patient-Centered Medical Home Pilot. J Gen Intern Med. 2016;31(3):289-296.

18. Fifield J, Forrest DD, Burleson JA, Martin-Peele M, Gillespie W. Quality and efficiency in small practices transitioning to patient centered medical homes: a randomized trial. J Gen Intern Med. 2013;28(6):778-786.

19. Gabbay RA, Bailit MH, Mauger DT, Wagner EH, Siminerio L. Multipayer patient-centered medical home implementation guided by the chronic care model. Jt Comm J Qual Patient Saf. 2011;37(6):265-273.

20. Liss DT, Fishman PA, Rutter CM, et al. Outcomes among chronically ill adults in a medical home prototype. Am J Manag Care. 2013;19(10): e348-e358.

21. Ezzati-Rice TM, Rohde F, Greenblatt J. Sample Design of the Medical Expenditure Panel Survey Household Component, 1998-2007. Methodology Report No. 22. March 2008. Agency for Healthcare Research and Quality, Rockville, MD. Available from: http://www.meps.ahrq.gov/ mepsweb/data_files/publications/mr22/mr22.pdf. Accessed February 24, 2018.

22. Agency for Healthcare Research and Quality [homepage on the Internet]. Clinical Classifications Software (CCS) for ICD-9-CM. Available from: http://www.hcup-us.ahrq.gov/toolssoftware/ccs/ccs.jsp. Accessed February 24, 2018. 
23. Medical Expenditure Panel Survey [homepage on the Internet]. MEPS HC-036: 1996-2008 Pooled estimation file. Agency for Healthcare Research and Quality, Rockville, MD. Available from: http://www.meps. ahrq.gov/mepsweb/data_stats/download_data/pufs/h36/h36u08doc. shtml\#30Survey. Accessed February 24, 2018.

24. Agency for Healthcare Research and Quality [homepage on the Internet]. Defining the PCMH. Available from: http://pcmh.ahrq.gov/page/ defining-pcmh. Accessed February 24, 2018.

25. Jones AL, Cochran SD, Leibowitz A. Usual primary care provider characteristics of a patient-centered medical home and mental health service use. J Gen Intern Med. 2015;30(12):1828-36.

26. Beal A, Hernandez S, Doty M. Latino access to the patient-centered medical home. J Gen Intern Med. 2009;24 Suppl 3:514-520.

27. Jerant A, Fenton JJ, Franks P. Primary care attributes and mortality: a national person-level study. Ann Fam Med. 2012;10(1):34-41.

28. Stockbridge EL, Philpot LM, Pagán JA. Patient-centered medical home features and expenditures by medicare beneficiaries. Am JManag Care. 2014;20(5):379-385.

29. Andersen RM. Revisiting the behavioral model and access to medical care: does it matter? J Health Soc Behav. 1995;36(1):1-10.

30. Rosenstock IM, Strecher VJ, Becker MH. Social learning theory and the health belief model. Health Educ Q. 1988;15(2):175-183.

31. Caliendo M, Kopeinig S. Some practical guidance for the implementation of propensity score matching. J Econ Surv. 2008;22(1): 31-72.

32. Philpot LM, Stockbridge EL, Padrón NA, Pagán JA. Patient-Centered Medical Home Features and Health Care Expenditures of Medicare Beneficiaries with Chronic Disease Dyads. Popul Health Manag. 2016;19(3):206-211.

33. Wasson J, Gaudette C, Whaley F, Sauvigne A, Baribeau P, Welch HG. Telephone care as a substitute for routine clinic follow-up. JAMA. 1992;267(13):1788-1793.

34. Lin DY, Psaty BM, Kronmal RA. Assessing the sensitivity of regression results to unmeasured confounders in observational studies. Biometrics. 1998;54(3):948-963.

35. Bodenheimer T, Berenson RA, Rudolf P. The primary care-specialty income gap: why it matters. Ann Intern Med. 2007;146(4):301-306.

36. Bodenheimer T, Pham HH. Primary care: current problems and proposed solutions. Health Aff (Millwood). 2010;29(5):799-805.

37. Bodenheimer T, Wagner EH, Grumbach K. Improving primary care for patients with chronic illness. JAMA. 2002;288(14):1775-1779.

38. Arend J, Tsang-Quinn J, Levine C, Thomas D. The patient-centered medical home: History, components, and review of the evidence. $M t$ Sinai J Med. 2012;79(4):433-450
39. McCarthy D, Mueller K, Wrenn J. Geisinger health system: Achieving the potential of system integration through innovation, leadership, measurement, and incentives. New York, NY: Commonwealth Fund; 2009.

40. Patient-Centered Primary Care Collaborative [homepage on the Internet]. A complete list of endorsers is available from the Patient-Centered Primary Care Collaborative at; 2015. Available from: https://www. pcpcc.org/membership. Accessed February 24, 2018.

41. Landon BE. Structuring payments to patient-centered medical homes. JAMA. 2014;312(16):1633-1634.

42. American Academy of Family Physicians, American Academy of Pediatrics, American College of Physicians, \& American Osteopathic Association. Joint principles of the patient-centered medical home; 2007. Available from: http:/www.aafp.org/dam/AAFP/documents/ practice_management/pcmh/initiatives/PCMHJoint.Pdf. Accessed February 24, 2018.

43. Institute of Medicine. Crossing the Quality Chasm: A New Health System for the 21st Century. Washington, D.C.: National Academy of Sciences; 2001.

44. Matlow AG, Wright JG, Zimmerman B, Thomson K, Valente M. How can the principles of complexity science be applied to improve the coordination of care for complex pediatric patients? Qual Saf Health Care. 2006;15(2):85-88.

45. American Academy of Family Physicians, American Academy of Pediatrics, American College of Physicians, American Osteopathic Association. Joint principles of a patient centered medical home. March 2007. Available from: http://www.aafp.org. Accessed February 21, 2018.

46. Martsolf GR, Alexander JA, Shi Y, et al. The patient-centered medical home and patient experience. Health Serv Res. 2012;47(6):2273-2295.

47. Bernstein RS, Meurer LN, Plumb EJ, Jackson JL. Diabetes and hypertension prevalence in homeless adults in the United States: a systematic review and meta-analysis. Am J Public Health. 2015;105(2):e46-e60.

48. Drawz PE, Bocirnea C, Greer KB, Kim J, Rader F, Murray P. Hypertension Guideline Adherence Among Nursing Home Patients. J Gen Intern Med. 2009;24(4):499-503.

49. Nielsen, M. Benefits of Implementing the Primary Care Patient-Centered Medical Home. Washington: Patient-Centered Primary Care Collaborative; 2012.

50. Garfield RL, Zuvekas SH, Lave JR, Donohue JM. The impact of national health care reform on adults with severe mental disorders. $\mathrm{Am}$ J Psychiatry. 2011;168(5):486-494
ClinicoEconomics and Outcomes Research

\section{Publish your work in this journal}

ClinicoEconomics and Outcomes Research is an international, peerreviewed open-access journal focusing on health technology assessment, pharmacoeconomics and outcomes research in the areas of diagnosis, medical devices, and clinical, surgical and pharmacological intervention. The economic impact of health policy and health systems

\section{Dovepress}

organization also constitute important areas of coverage. The manuscript management system is completely online and includes a very quick and fair peer-review system, which is all easy to use. Visit http://www.dovepress.com/testimonials.php to read real quotes from published authors. 